\title{
Hypothesis
}

\section{Osteoarthritis: The cause not result of joint failure?}

Osteoarthritis is an enigmatic condition as it is at once simple and complex. It seems simple as trauma is sufficient to produce its major features, but it becomes complex when we try to understand both 'primary' osteoarthritis and why the processes that are features of osteoarthritis develop. An enormous amount of information is available on the epidemiology, clinical picture, pathology, and biochemistry of osteoarthritis, but the problem is to see the patterns linking that information. Observation has established a set of features of osteoarthritis that any satisfactory hypothesis needs to explain.

Osteoarthritis is characterised by joint destruction with cartilage loss and occasional gross derangement of the joint's integrity. ${ }^{1}$ Osteoarthritis is homogeneous, ubiquitous, and related to age. ${ }^{23}$ The anatomical, histological, and biochemical features are present and constant to a remarkable degree in osteoarthritis at different sites and in different animals and animal models, though they may vary quantitatively. ${ }^{4}$ Paradoxically also, although osteoarthritis shows extraordinary diversity, it is heterogeneous, and this is shown in its aetiology. Joint insult of almost any kind may produce osteoarthritis. Cartilage abnormality from amino acid metabolism in ochronosis, trauma, and pre-existing inflammatory osteoarthritis may all produce this seemingly common pathway of a joint reacting to 'failure'. The clinical picture, pathology, and natural history are also very varied. ${ }^{4-6}$

Osteoarthritis has a characteristic joint distribution that is both spatial and temporal. Joints that are frequently involved include the first metatarsophalangeal, first carpometacarpal, distal interphalangeal, knee, and the apophyseal joints of the spine at the thoracolumbar and thoracocervical junctions. Conversely, others, such as the wrist, elbow, shoulder, ankle, and tarsal joints, are rarely involved. Usually the features are seen first at the metatarsophalangeal joint, and the sequence of involvement reflects the common site distribution. ${ }^{25}$

Remarkably, osteoarthritis is an anabolic as well as a destructive process. Bone sclerosis, capsular fibrosis, and osteophyte formation are the result of active turn on of systems producing tissue growth. The biochemistry of experimental osteoarthritis and of pathological specimens reflects this anabolism in an increase in cell activity and proteoglycan turnover. ${ }^{78}$ More remarkably, the proteoglycans are qualitatively different from those produced with aging; they are similar to the profile of 'juvenile' young cartilage..$^{9-11}$

Finally, to make the whole process seem totally contradictory some of its features may occur in isolation. Fibrillation of cartilage and 'age related osteophytes', which are features of osteoarthritis, may occur alone. ${ }^{112}$

Can a hypothesis be constructed to link these features? The primary approach is to see osteoarthritis as joint failure. If the joint is considered as a mechanical system, which it is, this allows an analogy with man-made machines. Joint failure is thus a function of use, material, and design, and this concept goes some way towards explaining then observed features. The heterogeneity reflects the multiple combinations of factors that interact to produce the osteoarthritic process. The distribution and age association reflect underdesign of joints. ${ }^{13}$ The homogeneity results from the triggering of the same final common pathway, the osteoarthritic process itself $^{6}$ (Fig. 1), and the anabolic response is then seen as an attempt at repair. ${ }^{14} 15$

The model though is not sufficient as it does not explain the nature of the anabolic response or why some features like osteophytes occur in isolation. It also gives no explanation for primary osteoarthritis. Is it simply that the aetiological factors are unidentified, or could the process develop in some other way? Possibly the process is a result of the failure of the normal maintenance of the joint-that is, a failure of remodelling. ${ }^{16} 17$ This concept can be taken further; rather than the process being driven

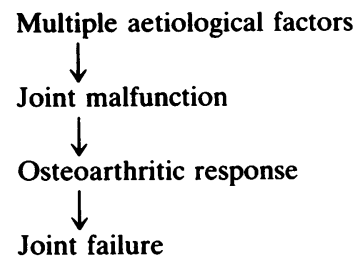

Fig. 1 The osteoarthritic process. 


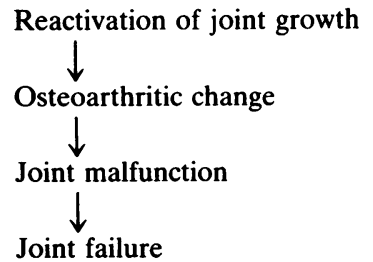

Fig. 2 Breakdown of joint control mechanisms.

by factors producing joint damage and triggering osteoarthritis, could it be the other way round? Perhaps joint tissue escapes from the normal control system maintaining the integrity of the joint, increases cell activity, and starts to grow. Is primary osteoarthritis due to reactivation of the control system that differentiates growth and maintains a joint? The disruption of function perhaps then follows and may progress to joint destruction. Primary osteoarthritis can then be seen as the result of intrinsic breakdown of joint control mechanisms (Fig. 2).

The breakdown of control then allows reactivation of processes involved in differentiation and growth that actually are the 'common pathway' of osteoarthritis. The mechanisms controlling growth are, however, ill understood. They depend on the interaction of a number of hormones, genes, and the way that the joints are loaded. ${ }^{18}$ Any mechanism is limited by the ability of the cell to contain a limited number of control and responder systems. This means that a number of different signals may produce a similar response, and thus the response of the joint is limited. Could osteoarthritis have only one mechanism, the mechanism that it has to carry because it was produced by it? Is osteoarthritis the reactivation of the system that produced the joint? In the first model the osteoarthritic process triggered by developing joint failure is the attempt at regeneration by activation of the joint's differentiation and growth system. In primary osteoarthritis this path is produced by breakdown of the control system itself.

There is no direct evidence for this. The conditions for it to be a possibility, however, can be defined and are real. Firstly, the joint needs to be able to grow, and, secondly, the features of osteoarthritis need to reflect the processes involved in normal tissue growth. Thirdly, spontaneous failure of controlling systems is possible. The joint needs to have underdesigned control systems. What is the evidence that these conditions are present in man?

Firstly, acromegaly provides us with an extraordinary natural experiment. ${ }^{19}$ Apparently, osteo- arthritis develops in longstanding untreated pituitary hyperfunction. Cartilage proliferates, and degenerative change develops as a secondary event, showing that cartilage has growth potential. At the end of normal growth cartilage proliferation must be controlled either by the absence of a stimulator or the presence of an inhibitor. It is not turned off irreversibly as metaphyseal bone growth is turned off by closing the switch of epiphyseal closure.

At maturity growth is certainly down graded to a level that is difficult to detect, but it is also hard to be sure that it has stopped. The precision of the local control mechanism is reflected in the delineation of the divides between bone, calcified cartilage, and joint cartilage. ${ }^{20}{ }^{21}$ Histologically the matrix changes its staining characteristics sufficiently abruptly to give a line referred to as the 'tide mark'. This zone may become focally unstable and start growing, thus triggering osteoarthritis. The reduplication of the tide mark seen in osteoarthritis may reflect that instability.

Secondly, do the processes in normal growth parallel the features of osteoarthritis? The development of an osteophyte reflects some of the features of the development of a joint. Thus a primitive cartilage model develops from a coalescence of mesenchymal cells, and at the same time a joint space forms between the 'bone'. Ossification centres then form in the bone, leaving a plate of growing cartilage, which allows bone lengthening to occur between primary and secondary ossification centres. $^{22-25}$ The cartilage overlying the secondary centre also continues to grow, allowing the joint surface to grow. The cartilage is a net of collagen under hydrophilic tension from a proteoglycan gel and to allow growth this net has to be enlarged. The earliest feature of experimental osteoarthritis is the swelling of cartilage. Does this represent an attempt at net enlargement and growth? The bone stops growing when the epiphyseal plate is closed by ossification, but the cartilage at the osteochondral junction remains a potential unossified growth plate. Formation of osteophyte follows a not dissimilar pattern in experimental models, with peripheral mesenchymal cells proliferating, undergoing chondroid change, and then ossifying. ${ }^{26} 27$ The cartilage loss, bone sclerosis, and cyst formation are secondary mechanical effects.

Thirdly, are some joints underdesigned? Are the functional requirements of a joint at the limit of its tolerance, so that it has little functional reserve? As the functional capacity of a joint is unknown it is not possible to answer this question directly. ${ }^{28} 29$ It is possible, however, to look at the period of evolution of joints and at the changes that have occurred and thus to see the relative changes that have altered the 
functional requirement of joints. Change in loading patterns means that some joints are loaded less and are relatively overdesigned, whereas others are loaded more and will be relatively underdesigned.

Bipedalism has not been present for long and probably the modern skeleton has both underdesigned and overdesigned components. The earliest evidence of a bipedal hominid is found in the footprints of an adult and child at Laetoli in Tanzania, 3.75 million years old. These show a definite striding gait, but the fossil record shows that the bone configuration was not fully adapted for bipedalism. ${ }^{30}{ }^{31}$ Anatomically modern humans are much more recent and remains like those at Mungo in Australia are only 32000 years old ${ }^{32}$ Analysis of mutations in mitochondral DNA and protein sequencing suggest the emergence of modern man about 200000 years ago. ${ }^{33}$

Diarthrodial joints have been present for a long time. They first developed during the Ordovician period in jawless fishes, the ostracoderms of about 450 million years ago. The materials used, however, have been available for many years. Quadripedal locomotion was tested for over 200 million years before the earliest mammals emerged in the early Caenozoic period about 70 million years ago. Comparison of the skeleton of fossil apes, like Proconsul, or modern apes, like the chimpanzee, with modern man shows the dramatic changes in joints that have taken place with the emergence of bipedalism. ${ }^{34-36}$

In man's recent emergence there are other major changes that have imposed new demands on the functional capacity of the joint. Body size is over twice that of $A$ afarensis, ${ }^{31}$ and there is a change in both chronological and biological age. Determination of age of the remains of $H$ neanderthalis suggests that few lived beyond the age of 40 years. ${ }^{37}$ A long chronological age is new and the functional demand that it puts on joints is new: the strain should show on the more underdesigned joints. Biological age has changed even more dramatically and, in particular, the change in hormonal status of woman with the menopause means that a postreproductive period now occurs. The menopause is associated with development of polyarticular osteoarthritis. 3839 Baboon, rodent, and dog cartilage contains oestrogen receptors ${ }^{40-42}$; the systems controlling cartilage maintenance must therefore need moderating as oestrogen levels change. As such dramatic changes in function and age have occurred in man over such a short period of time the joints must vary in functional reserve and some are likely to be underdesigned.

The evolutionary story of the joint gives other insights suggesting that the potential for joint regeneration may persist in some form. The lower

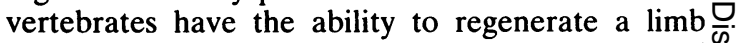
with functional joints. This is 'lost' in reptiles and mammals, but there is some evidence that it persists $\overrightarrow{\vec{D}}$ in the embryonic phase of rats and perinatally in the 0 opossum. ${ }^{4-45}$ Reptiles and amphibians also grow throughout their long lives. ${ }^{46}$ The chronological $\frac{\overline{\bar{c}}}{}$ lifetime of a poikilotherm may be less demanding $\widehat{\widehat{\alpha}}$ than that of a more active homeotherm, but indicates, nevertheless, that time alone does not ${ }^{\infty}$ give osteoarthritis; the aging process is more com- $\vec{O}$ plex. ${ }^{47}$ In captivity mammals live for long periods $\overrightarrow{\vec{\omega}}$ and show senescent change, including osteoarthritis. $\mathscr{N}$ Monkeys develop spinal osteoarthritis, but patterns of appendicular changes have not been studied. ${ }^{48} \stackrel{\bar{O}}{\circ}$

The biological perspective shows that the types of $\stackrel{\vec{p}}{\vec{p}}$ mechanism involved in joint formation may be the basis of those seen in osteoarthritis. Thus the $\bar{c}$ homogeneity of the process, its anabolism, and $\infty$ characteristic osteophyte formation can be under-음 stood as the reactivation of growth and differentia- tion processes that are suppressed with the achieve- $Z$ ment of skeletal maturity. Qualitative variation in the level of control failure may explain such 3 elements as the age related osteophyte with local ${ }_{\mathbb{D}}^{\circ}$ intrinsic disinhibition of growth at a level that doess not disorganise the joint mechanically. Intrin $\mathbb{A}_{\infty}^{\infty}$ osteoarthritis will occur in time in the relative underdesigned joints, giving the usual spatial dist?응 bution. The heterogeneity of osteoarthritis though is unrelated, reflecting the fact that the model is complementary to the traditional wear and tear hypothesis of Fig. 1. Heterogeneity reflects the $\stackrel{\square}{\unrhd}$ multiple causes disrupting joint function and the $\overrightarrow{\vec{F}}$ complex interaction of mechanical factors acting on $\frac{3}{3}$ a disorganised mechanical system, the osteoarthritic $\vec{\supset}$ joint.

A hypothesis introduces the risk of both obscure conjecture and teleology, but to advance understanding of osteoarthritis a new conceptual frame is needed. Reflection on the way in which joints came to form, by evolution and by embryogenesis, may。 allow us to make the necessary conceptual leap. This hypothesis suggests mechanisms intrinsic to the joints' function that can explain the key features of $\supset$ osteoarthritis. It suggests that understanding of jointo biology rather than just clinical observation will provide the insights necessary for its control in theos future.

Dept of Rheumatology,

Mount Gould Hospital,

Mount Gould Road,

Plymouth PL4 7QD

\section{References}

C w HUTTON

1 Sokoloff L. The biology of degenerative joint disease. Chicago: University of Chicago Press, 1969. 
2 Heine J. Uber die Arthrits deformans. Virchows Archiv 1923; 260: 521-663.

3 Lawrence J S. Generalised osteoarthritis in a population sample. Am J Epidemiol 1969; 90: 381-9.

4 Bland J H, Cooper S M. Osteoarthritis: a review of the cell biology involved and evidence for reversibility. Nianagement rationally related to known genesis and pathophysiology. Semin Arthritis Rheum 1984; 14: 106-33.

5 Peyron J G. Epidemiologic and etiologic approach of osteoarthritis. Semin Arthritis Rheum 1979; 8: 288-306.

6 Radin E L, Paul I L, Rose R M. Osteoarthritis as a final common pathway. In: Nuki G, ed. The aetiopathogenesis of osteoarthritis. London: Pitman Medical, 1979: 84-9.

7 Mankin H J, Johnson M E, Lippiello L. Bioch:mical and metabolic abnormalities in articular cartilage from osteoarthritic human hips. III. Distribution and metabolism of amino sugar containing macromolecules. J Bone Joint Surg [Am] 1981; 63: 131-9.

8 McDevitt C A, Billingham M E J, Muir $H$. In vivo metabolism of proteoglycans in experimental osteoarthritic and normal canine articular cartilage and the intervertebral disc. Semin Arthritis Rheumatism 1981; 11 (suppl 1): 17-18.

9 Roughley $P$ J. Structural changes in the proteoglycans of articular cartilage during aging. J Rheumatol [Spec Issue] 1987; 14: 14-15.

10 Caplan A I. Cartilage. Sci Am 1984; 251 : 84-7.

11 Adams M E, Grant M D, Ho A. Cartilage proteoglycan changes in experimental canine osteoarthritis. J Rheumatol [Spec Issue] 1987; 14: 107-9.

12 Danielson L, Hernborg S. Clinical and roentogenographic study of knee joints with osteophytes. Clin Orthop 1970; 69: 302-12.

13 Hutton C W. Generalised osteoarthritis, an evolutionary problem. Lancet 1987; i: 1463-5.

14 Luyten F P, Verbruggen G, Veys E M, Goffin E, De Pypere H. In vitro repair potential of articular cartilage: proteoglycan metabolism in the different areas of the femoral condyles in human cartilage explants. $J$ Rheumatol 1987; 14: 329-34.

15 Sokoloff L. Cell biology and the repair of articular cartilage. J Rheumatol 1974; 1: 9-16.

16 Sokoloff $\mathrm{L}$. Osteoarthritis as a remodelling process. $J$ Rheumatol [Spec Issue] 1987; 14: 7-10.

17 Johnson L C. Joint remodeling as the basis for osteoarthritis. J Am Vet Med Assoc 1962; 141: 1237-41.

18 Cruess R. Growth and its control. In: Cruess R L, ed. Musculoskeletal system-embryology, biochemistry, and physiology. Edinburgh: Churchill Livingstone, 1982: 191-217.

19 Layton M W, Fudman E J, Barkan A, Braunsten E M, Fox I H. Acromegalic arthropathy. Arthritis Rheum 1988; 31: 1022-7.

20 Ghadially F N, Subimal R. Fine structure of synovial joints in health and disease. New York: Plenum, Appleton-CenturyCrofts, 1983.

21 Green W T Jr, Martin G M, Eanes E D, Sokoloff L. Microradiographic study of the calcified layer of articular cartilage. Archives of Pathology 1970; 90: 151-8.

22 Fell H B. The histogenesis of cartilage and bone in the long bones of the embryonic chick. Journal of Morphology and Physiology 1925; 40: 417-59.

23 Amprino R. The early rudiment of the shaft bone. Anat Embryol (Berl) 1980; 160: 53-75.

24 Mitrovic D R. Development of the metatarsophalangeal joint of the chick embryo: morphological, ultrastructural and histochemical studies. Am J Anat 1977; 150: 333-48.
25 Zwilling E. Limb morphogenesis. Advances in Morphogenesis 1961; 1: 301-30.

26 Moskowitz R W, Goldberg V M. Studies of osteophyte pathogenesis in experimentally induced osteoarthritis. $J$ Rheumatol 1987; 14: 311-20.

27 Gilbertson E M M. Development of periarticular osteophyte in experimentally induced osteoarthritis in the dog. Ann Rheum Dis 1975; 34: 12-25.

28 Radin E L. The physiology and degeneration of joints. Semin Arthritis Rheum 1972; 2: 245-57.

29 Paul J P. Forces transmitted by joints in the human body. Proceedings of the Institute of Mechanical Engineers 1966-7; 181: $9-15$.

30 Day M H, Wickens E H. Laetoli Pliocene hominid footprints and bipedalism. Nature 1980; 286: 385-7.

31 Johanson D C, Lovejoy C O, Kimbel W H, et al. Morphology of the Pliocene partial hominid skeleton (AD 288-1) from the Hadar formation, Ethiopia. Am J Phys Anthropol 1982; 57: 403-52.

32 Thorne A G. Mungo and the Kow swamp: morphological variation in Pleistocene Australians. Mankind 1971; 8: 85-9.

33 Cann R L, Stoneking M, Wilson A C. Mitochondral DNA and human evolution. Nature 1987; 325: 31-6.

34 Day M H. Bipedalism, pressures, origins and modes, 1888- . . In: Wood B, Martin L, Andrews P, eds. Major topics in primate and human evolution. Cambridge: Cambridge University Press, 1986.

35 Walker A, Teaford M. The hunt for Proconsul. Sci Am 1989; 2680: 58-65.

36 Napier J R, Davis P R. The fore limb skeleton and associated remains of Proconsul africanus. Fossil Mammals of Africa 1959; 16: 1-69.

37 Trinkaus E, Thompson D D. Femoral diaphyseal histomorphometric age determinations for the Shanidar 3, 4, 5, and 6 Neandertals and Neandertal longevity. Am J Phys Anthropol 1987; 72: 123-9.

38 Cecil R L, Archer B H. Classification and treatment of chronic arthritis. JAMA 1926; 87: 741-6.

39 Kellgren J H, Moore R. Generalised osteoarthritis and Heberden's nodes. Br Med J 1952; i: 181-7.

40 Sheridan P J, Aufdemorte T B, Holt G R, Gates G A. Cartilage of the baboon contains estrogen receptors. Rheumatol Int 1985; 5: 279-81.

41 Young P C M, Stack M T. Oestrogen and glucocorticoid receptors in adult canine articular cartilage. Arthritis Rheum 1982; 25: 568-73.

42 Rosner I A, Manni A, Malemud C, Boja B, Moskowitz K W. Estrogen receptors in articular chondrocytes. Biochem Biophys Res Commun 1982; 10: 1378-82.

43 Morgan T H. The extent and limitations of the power to regenerate in man and other vertebrates. Philadelphia: Lippincott, 1906: 219-29. (The Harvey lectures.)

44 Mizell $M$. Limb regeneration: induction in the new born opossum. Science 1968; 161: 283-6.

45 Deuchar E M. Regeneration of amputated limb buds in early rat embryos. J Embryol Exp Morphol 1976; 35: 345-54.

46 Romer A S. Osteology of the reptiles. Chicago: University of Chicago Press, 1956.

47 Davies I. Biology of aging - theories of aging. In: Brocklehurst J C, ed. Geriatric medicine and gerontology. London: Churchill Livingstone, 1985: 62-81.

48 DeRousseau C J. Aging in the musculoskeletal system of rhesus monkeys: degenerative joint disease. Am J Phys Anthropol 1985; 67: 177-84. 